\title{
Bridging the Divide
}

This coming September will mark 40 years since I became an optometry student at the

1 University of Waterloo (UW). There has been much progress in our profession since 1975 , notably in the technology we use for diagnosis and management of our patients' oculovisual problems and in the resulting interactions with other health professionals.

In the "good old days" (really?) optometrists encountered a lot of resistance, if not outright hostility, from some other health professions. Even at UW, I recall that into the 1980s, optometry faculty had a hard time being recognized by some quarters of the University as true scholars, let alone scientists and clinicians in their own right. Our professional relationships with organized medicine, particularly ophthalmological organizations, could sometimes best be described as toxic.

With the passage of time, things have changed a great deal, mostly for the better. Although ODs are sometimes still discouraged from attending certain ophthalmology conferences, for the most part the welcome mat is there. For example, optometric research is well represented at the annual conference of the Association for Research in Vision and Ophthalmology (ARVO), and many papers from optometric researchers appear in ARVO's flagship publication Investigative Ophthalmology and Vision Science and other major ophthalmological and vision science peer-reviewed journals.

In clinical practice, we have seen the rapid development of co-management of various clinical conditions by optometrists and ophthalmologists, much more collegial interactions between practitioners than was the norm when I was a newly graduated optometrist, and much more collaboration. A good example is "Brief Guide for Primary Care Physicians - Glaucoma" (http://opto.ca/document/primary-care-physician-guide-glaucoma), which was prepared by a team of optometrists and ophthalmologists. The trend toward multidisciplinary collaboration in clinical care and research is a healthy one and should benefit our patients.

On our website, you will find the newest result of the collaboration between optometry and ophthalmology. The Eye Health Council of Ontario has produced a new Guideline on management of age-related macular degeneration (AMD). This document lays out the roles of health care providers in the diagnosis and management of patients with AMD and provides family physicians and nurse practitioners with important guidance on how to support these patients. Although it was written for Ontario practitioners, the information is useful to all ODs across Canada. I hope you will enjoy reading it.

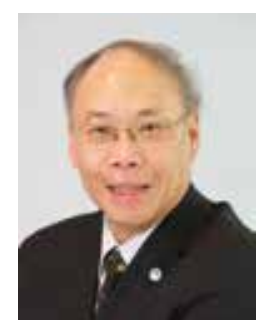

\section{B. Ralph Chou, MSc, OD, FAAO Editor-in-Chief}

